\title{
High mucosal cytomegalovirus DNA helps predict adverse short-term outcome in acute severe ulcerative colitis
}

\author{
Saransh Jain ${ }^{1}$, Divya Namdeo $^{2}$, Pabitra Sahu ${ }^{1}$, Saurabh Kedia ${ }^{1}$, Peush Sahni ${ }^{3}$, Prasenjit Das ${ }^{4}$, Raju Sharma ${ }^{5}$, \\ Vipin Gupta ${ }^{6}$, Govind Makharia ${ }^{1}$, Lalit Dar ${ }^{2}$, Simon PL Travis ${ }^{6}$, Vineet Ahuja ${ }^{1}$ \\ Departments of ${ }^{1}$ Gastroenterology, ${ }^{2}$ Microbiology, ${ }^{3}$ Gastrointestinal Surgery, ${ }^{4}$ Pathology, and ${ }^{5}$ Radiodiagnosis, All India Institute of Medical \\ Sciences, New Delhi, India; ${ }^{6}$ Translational Gastroenterology Unit, NIHR Oxford Biomedical Research Centre, Oxford University Hospitals NHS \\ Foundation Trust, John Radcliffe Hospital, Oxford, UK
}

Background/Aims: Predictors of short-term outcome of intravenous (IV) steroid therapy in acute severe ulcerative colitis (ASUC) have been well described, but the impact of cytomegalovirus (CMV) infection as a predictor of outcome remains debatable. We investigated the role of quantitative CMV polymerase chain reaction (PCR) as a predictor of short-term outcome in patients with ASUC. Methods: Consecutive patients with ASUC satisfying Truelove and Witts criteria hospitalized at All India Institute of Medical Sciences (AIIMS) from May 2016 to July 2019 were included; all received IV steroid. The primary outcome measure was steroid-failure defined as the need for rescue therapy (with ciclosporin or infliximab) or colectomy during admission. AIIMS' index (ulcerative colitis index of severity $>6$ at day $1+$ fecal calprotectin $>1,000 \mu \mathrm{g} / \mathrm{g}$ at day 3 ), with quantitative CMV PCR on biopsy samples obtained at initial sigmoidoscopy were correlated with the primary outcome. Results: Thirty of 76 patients (39\%) failed IV corticosteroids and $12(16 \%)$ underwent surgery. Patients with steroid failure had a significantly higher mucosal CMV DNA than responders (3,454 copies/mg $[0-2,700,000]$ vs. 116 copies/mg [0-27,220]; $P<0.01)$. On multivariable analysis, mucosal CMV DNA load $>2,000$ copies/mg (odds ratio $[\mathrm{OR}], 10.2 ; 95 \%$ confidence interval $[\mathrm{CI}], 2.6-39.7 ; P<0.01)$ and AIIMS' index (OR, 39.8; 95\% CI, 4.4-364.4; $P<0.01$ ) were independent predictors of steroid-failure and need for colectomy. The combination correctly predicted outcomes in $84 \%$ of patients with ASUC. Conclusions: High mucosal CMV DNA ( $>2,000$ copies $/ \mathrm{mg})$ independently predicts failure of IV corticosteroids and short-term risk of colectomy and it has an additional value to the established markers of disease severity in patients with ASUC. (Intest Res 2021;19:438-447)

Key Words: Colitis ulcerative; Steroid failure; Prediction; Cytomegalovirus

\section{INTRODUCTION}

Acute severe ulcerative colitis (ASUC) as defined by Truelove and Witts criteria is a medical emergency requiring hospitalization and time bound management. ASUC complicates the

Received May 23, 2020. Revised July 8, 2020. Accepted July 8, 2020. Correspondence to Vineet Ahuja, Department of Gastroenterology, All India Institute of Medical Sciences, Room No. 3093, 3rd floor, Academic Building, New Delhi 110029, India. Tel: +91-11-26593300, Fax: +91-11-2658663,

E-mail:vineet.aiims@gmail.com course of ulcerative colitis (UC) in up to $25 \%$ of cases with a third of these episodes being the presentation of UC. ${ }^{1,2}$ Intravenous (IV) steroids remain first-line therapy for ASUC, but only $60 \%$ patients respond to IV steroids, with the rest requiring rescue in the form of advanced immunosuppression (infliximab or ciclosporin) or surgery. ${ }^{3}$ It is clinically highly relevant to predict steroid nonresponse in order to identify patients who need a change in treatment strategy to improve outcomes, both in the short and medium term. Baseline endoscopic severity, stool frequency, C-reactive protein (CRP) at 
day 3 and fecal calprotectin (FCP) at day 3 have been correlated with short-term outcomes in ASUC during the index admission. ${ }^{4.7}$ Our previous study described the All India Institute of Medical Sciences (AIIMS)' index (a prediction score comprising-baseline ulcerative colitis endoscopic index of severity [UCEIS] $>6 / 8$ and day $3 \mathrm{FCP}>1,000 \mu \mathrm{g} / \mathrm{g}$ ) and its high positive predictive value (100\%) in predicting steroid nonresponse in patients with ASUC. ${ }^{6}$ Apart from predicting nonresponse to steroids, the index provides a way of determining the impact of external factors on short-term outcome, including cytomegalovirus (CMV) infection.

CMV being reported in colonic tissue in $33 \%-36 \%$ of steroid refractory colitis has been postulated as one of the reasons for flare of UC. ${ }^{8}$ However it is still not clear whether CMV primarily worsens the inflammation in patients with severe UC or is a secondary phenomenon, and merely a marker of severe disease. ${ }^{9-11} \mathrm{CMV}$ infection is conventionally diagnosed by presence of inclusion bodies on histopathological examination and immunohistochemistry (IHC) against CMV antigen, but these methods are time consuming and results are usually not available at day 3 of IV corticosteroid therapy when decision for stepping up immunosuppression is required. Quantitative CMV polymerase chain reaction (PCR) in mucosal tissue has a rapid turnaround time and can be used to identify CMV infection in ASUC. It has also been found to predict CMV IHC positivity. ${ }^{12-15}$ However, the significance of CMV mucosal PCR and high viral load on the outcomes in ASUC is still debatable. Moreover, whether CMV adds to the predictive value of existing severity indices, remains unknown. The present study was therefore designed to evaluate the role of quantitative mucosal CMV PCR as a predictor of outcomes in patients with ASUC and to find out whether it adds to previously defined predictors of short-term outcomes.

\section{METHODS}

\section{Patients}

All patients with ASUC defined by Truelove and Witts criteria (6 or more stools with blood and 1 or more of following: hemoglobin $<10.5 \mathrm{~g} / \mathrm{dL}$, erythrocyte sedimentation rate $>30$ $\mathrm{mm} / \mathrm{hr}$, fever $>37.8^{\circ} \mathrm{C}$, or tachycardia $>90 / \mathrm{min}$ ) who were hospitalized at AIIMS, New Delhi from May 2016 to July 2019 were screened for inclusion. ${ }^{16,17}$ Secondary referrals, children $<18$ years and patients who had detectable Clostridioides difficile toxin were excluded.

\section{Ethical Considerations}

The study was approved by Institute Review Board of AIIMS (IRB No. IESC/T-277) and all patients gave written informed consent.

\section{Definitions}

\section{1) Ulcerative Colitis}

Diagnosis of UC was based on clinical, radiologic and histological criteria. ${ }^{18}$ Patients with index presentation of ASUC that later turned out to be infection or Crohn's colitis were excluded.

\section{2) Steroid-Failure}

Patients of ASUC who required rescue medical therapy (IV cyclosporine $2 \mathrm{mg} / \mathrm{kg}$ for up to 7 days, oral tacrolimus $0.1-0.2$ $\mathrm{mg} / \mathrm{kg}$ or infliximab $5 \mathrm{mg} / \mathrm{kg}$ ) or surgery during index hospitalization were defined as steroid failure patients.

\section{3) Disease Extent}

Disease extent was defined as maximum macroscopic extent at colonoscopy preceding ASUC according to Montreal classification. ${ }^{19}$ For patients presenting with ASUC at diagnosis, extent was determined from the first colonoscopy after discharge or the surgical specimen if they underwent colectomy.

\section{4) Prior Steroid Use}

It is defined as any use of systemic steroids prior to the episode of ASUC. Steroid use in first year of diagnosis: it included patients who received steroids of any form (oral or IV) in their first year after diagnosis.

\section{5) Ulcerative Colitis Endoscopic Index of Severity}

The endoscopic disease severity was assessed with UCEIS which the sum of 3 descriptors: vascular pattern (scored 0-2); bleeding (scored 0-3); erosions and ulcers (scored 0-3), range $0-8$, assessed in the most severely affected area at flexible sigmoidoscopy. ${ }^{20}$

\section{6) AIIMS' Index}

It is a simple predictive score based on 2 objective parameters; (1) UCEIS assessed on the day of admission and (2) FCP measured on day 3 of IV steroid. It is calculated with the following formula: baseline UCEIS >6+day 3 FCP $>1,000 \mu \mathrm{g} / \mathrm{g}$ (where FCP $>1,000 \mu \mathrm{g} / \mathrm{g}=1$ and UCEIS $>6=1$; and $\mathrm{FCP} \leq 1,000 \mu \mathrm{g} / \mathrm{g}$ $=0$ and UCEIS $\leq 6=0$ ). The score ranged from 0 to 2 . Patients who fulfilled both the criteria ( $\operatorname{score}=2$ ) are considered 
AIIMS' index positive. $^{6}$

\section{7) Short-Term Outcome}

It was defined as outcome during index admission (steroid failure as defined above).

\section{8) CMV IHC}

Sections cut from colonic biopsy blocks were subjected to the mouse monoclonal antibody against CMV stain (Clone CCH2 + DDG9; dilution 1:100, DAKO, Glostrup, Denmark). Endogenous peroxidase was blocked using $4 \%$ hydrogen peroxide, followed by antigen retrieval by boiling in citrate buffer. Standard overnight staining protocol was followed. The reaction product was developed with 3,3'-diaminobenzidine and counterstained with hematoxylin. Appropriate positive and negative controls were used. IHC stain was taken as positive when strong inclusion like positivity was noted in the tissue sections.

\section{9) Quantitative CMV PCR}

Quantitation of CMV DNA was performed on colonic mucosal samples by real-time PCR. DNA for real-time PCR assay was extracted from mucosal samples by using the DNAeasy Blood and tissue kit (Qiagen, cat no- 69506, Hilden, Germany) as per the manufacturer's instructions. The CMV DNA load was expressed as CMV DNA copies per milligram of mucosal tissue biopsy. The oligonucleotide primers used for quantitative CMV-DNA determination were derived from a highly conserved $\mathrm{AD}-1$ region of glycoprotein $\mathrm{B}(\mathrm{gB})$ gene. ${ }^{21}$ Human genomic sequence glyceraldehyde-3-phosphate dehydrogenase (GAPDH) gene was used as an internal control for the quantitative real-time PCR assay as described previously. ${ }^{22}$ For quantification, a plasmid DNA containing the target sequence of $\mathrm{gB}$ gene was used as standard. The standard curve was established, by employing serial logarithm dilutions covering a range of 7 logs. The CMV standard along with the test samples were quantified in duplicate, and the mean values were used to calculate the CMV load. Lab personnel were blinded to the outcomes. It takes 3 to 4 days to get report of quantitative CMV PCR in a biopsy specimen in our set up.

\section{Study Design}

It was a prospective observational cohort study. Patients' details were collected on baseline demographics, prior therapy for UC, endoscopic assessment of severity (UCEIS) by unprepared flexible sigmoidoscopy within 24 hours of admission and biopsies taken in saline and formalin for quantitative
CMV PCR and CMV IHC respectively. Clinical observations of pulse rate, temperature, blood pressure, stool frequency and laboratory parameters during the hospital stay were recorded. Serum CRP and FCP performed on day 3 of IV steroid therapy and fecal samples were taken on admission for culture, $C$. difficile toxin assay by ELISA (enzyme-linked immunosorbent assay). Day of admission was counted as day 1.

The outcome measure was failure to respond to IV steroid therapy as defined above.

\section{Management}

All patients received IV and rectal hydrocortisone (400 mg/ day IV, $200 \mathrm{mg} /$ day per rectum), whilst continuing 5-ASA (5-aminosalicylic acid) therapy, according to guidelines, as well as antibiotics (ciprofloxacin and metronidazole), given the prevalence of gastrointestinal infection in India. Blood transfusion was given as required (hemoglobin $<80 \mathrm{~g} / \mathrm{L}$ ). ${ }^{16}$ Oxford criteria were used to identify patients at high risk of colectomy and if unresponsive to 5-7 days of IV steroids, rescue therapy or colectomy was advised. ${ }^{4}$ The option of medical therapy with infliximab/cyclosporine versus surgery was given upfront to the patients (at day 5-7), and the decision was made after joint medical-surgical review and patient counselling (given the prohibitive cost of these therapies in the developing world many patients opted for surgery before any rescue therapy). Patients responding to IV steroids were discharged on $40 \mathrm{mg} /$ day prednisolone with a taper period of 3 to 4 months, along with azathioprine.

\section{Statistical Analysis}

Continuous variables are expressed as the mean \pm standard deviation and non-Gaussian distribution as median and range. Categorical variables are summarized as frequencies with percentages. To avoid decimal points, percentages were rounded up. Quantitative variables on admission were compared using Student $t$-test or Mann-Whitney $U$ test and qualitative variables by chi-square test. Comparison of the means of continuous variables for 2 groups was based on analysis of variance or the nonparametric Kruskal-Wallis test, where indicated. Receiver operator characteristic curves were used to identify cutoff with optimal sensitivity and specificity. Clinically relevant variables with $P$-values $<0.1$ were included for multivariable analysis, which was performed for steroid-failure as outcome variable. $P$-values $<0.05$ were considered statistically significant. Analyses were performed using SPSS software version 24.0 (IBM Corp., Armonk, NY, USA). 


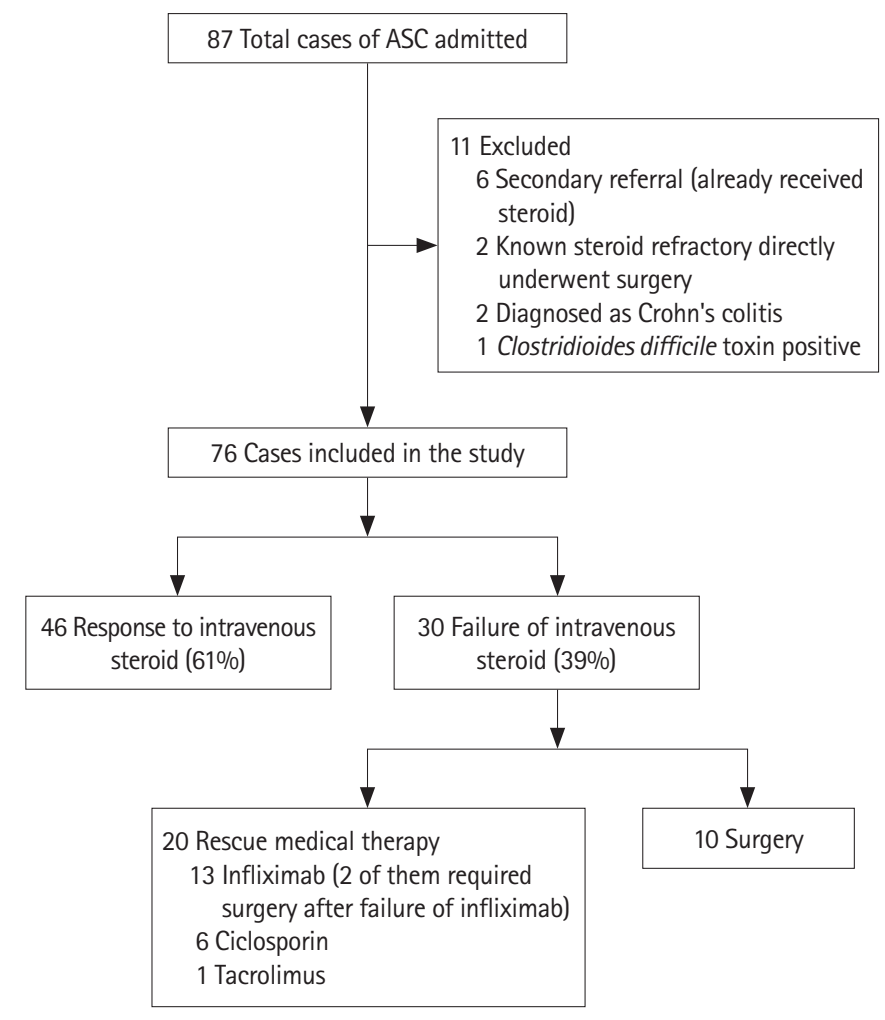

Fig. 1. CONSORT diagram: study population. ASC, acute severe colitis.

\section{RESULTS}

\section{Patients}

Eighty-seven patients with ASUC were hospitalized during the study period; 11 patients were excluded (Fig. 1), and 76 were finally included in the study. Forty-six patients (61\%) responded to IV steroid and 30 patients (39\%) had steroid failure. Of these, 20 patients received rescue medical therapy ( 6 ciclosporin, 1 tacrolimus, and 13 infliximab) and 12 (16\%) required surgery, including 2 patients after failure of rescue infliximab therapy.

\section{Baseline Demographic and Clinical Characteristics}

Mean age at admission was $35.5 \pm 12.1$ years, with $53 \%$ males and $8 \%$ patients presented with ASUC at diagnosis (see Table 1 for demographics). Patients in the steroid failure group had a higher frequency of steroid use in the first year of diagnosis compared to steroid responders (though not statistically significant) $(22 / 30$ [73\%] vs. $27 / 46$ [59\%]; $P=0.15)$. There was no difference between the 2 groups with respect to age of presentation, sex, extent and duration of disease, presence of extraintestinal manifestation, prior ASUC, prior use of azathioprine and systemic steroids (Table 1).

Table 1. Baseline Demographics and Disease Phenotypes of Patients of ASUC and Comparison of Steroid Responders with Steroid Failures

\begin{tabular}{|c|c|c|c|c|}
\hline Variable & $\begin{array}{l}\text { Total patients } \\
(n=76)\end{array}$ & $\begin{array}{l}\text { Steroid responder } \\
\qquad(n=46)\end{array}$ & $\begin{array}{l}\text { Steroid failure } \\
\quad(n=30)\end{array}$ & $P$-value \\
\hline Age (yr) & $35.5 \pm 12.1$ & $34.2 \pm 10.0$ & $37.4 \pm 12.2$ & 0.91 \\
\hline Male sex & 40 (53) & $23(50)$ & $17(56)$ & 0.42 \\
\hline Duration of UC prior to ASC (mo) & $12(1-180)$ & $12(1-180)$ & $18(6-120)$ & 0.51 \\
\hline Index presentation of UC as ASUC & $6(8)$ & $4(9)$ & $2(7)$ & 0.53 \\
\hline Extent & & & & 0.92 \\
\hline E2 (left-sided colitis) & $20(26)$ & $12(26)$ & $8(27)$ & \\
\hline E3 (extensive colitis) & $56(74)$ & $34(74)$ & $22(73)$ & \\
\hline Prior azathioprine use & $34(45)$ & $21(46)$ & $13(43)$ & 0.51 \\
\hline Previous ASUC & $18(24)$ & $9(20)$ & $9(30)$ & 0.73 \\
\hline Prior systemic steroid use & $60(79)$ & $35(76)$ & $25(83)$ & 0.61 \\
\hline Steroid use in 1st year of diagnosis of UC & $49(64)$ & $27(59)$ & $22(73)$ & 0.15 \\
\hline Tobacco user & $14(18)$ & $8(17)$ & $6(20)$ & 0.42 \\
\hline \multirow[t]{4}{*}{ Presence of EIMs } & $27(35)$ & $16(35)$ & $11(37)$ & 0.91 \\
\hline & & 13 Central or peripheral arthralgia & 9 Central or peripheral arthralgia & \\
\hline & & 2 Episcleritis & 1 Episcleritis & \\
\hline & & 1 Primary sclerosing cholangitis & 1 Pyoderma gangrenosum & \\
\hline
\end{tabular}

Values are presented as mean \pm standard deviation, number (\%), or median (range).

ASUC, acute severe ulcerative colitis; UC, ulcerative colitis; ASC, acute severe colitis; EIMs, extraintestinal manifestations. 
Table 2. Clinical and Laboratory Parameters in Patients of Acute Severe Ulcerative Colitis and Comparison of Steroid Responders with Steroid Failures

\begin{tabular}{|c|c|c|c|c|}
\hline Variable & Total patients $(n=76)$ & Steroid responder $(n=46)$ & Steroid failure $(n=30)$ & $P$-value \\
\hline Stool frequency on admission (/day) & $10(6-20)$ & $9(6-20)$ & $11(9-18)$ & 0.11 \\
\hline 1 & $18(24)$ & $12(26)$ & $6(20)$ & \\
\hline$>3$ & $23(30)$ & $8(17)$ & $15(50)$ & \\
\hline Day 3 stool frequency (/day) & $7(2-12)$ & $5(2-15)$ & $7(4-14)$ & 0.06 \\
\hline Hemoglobin on admission ( $\mathrm{g} / \mathrm{dL})$ & $9.3 \pm 2.3$ & $9.4 \pm 2.2$ & $9.2 \pm 2.2$ & 0.81 \\
\hline ESR on admission (mm/hr) & $46(20-82)$ & $41(22-78)$ & $47(20-82)$ & 0.45 \\
\hline Albumin on admission ( $\mathrm{g} / \mathrm{L})$ & $2.9 \pm 0.7$ & $3.0 \pm 0.7$ & $2.8 \pm 0.7$ & 0.16 \\
\hline Positive tissue CMV PCR & $45(59)$ & $24(52)$ & $21(70)$ & 0.15 \\
\hline Mucosal CMV DNA load (copies/mg) & $260(0-2,700,000)$ & $116(0-27,220)$ & $3,454(0-2,700,000)$ & $<0.01$ \\
\hline UCEIS on admission & $5(3-8)$ & $5(3-7)$ & $6(4-8)$ & 0.04 \\
\hline UCEIS > 6 & $21(28)$ & $6(13)$ & $15(50)$ & $<0.01$ \\
\hline Day 3 FCP $(\mu \mathrm{g} / g)$ & $1,115.8(44.2-7,427.0)$ & $747.0(44.2-4,062.0)$ & $1,383.8(330.0-7,427.0)$ & $<0.01$ \\
\hline Day 3 FCP $>1,000 \mu \mathrm{g} / \mathrm{g}$ & $40(53)$ & $16(35)$ & $24(80)$ & $<0.01$ \\
\hline AllMS' index (score = 2) & $15(20)$ & $1(2)$ & $14(47)$ & $<0.01$ \\
\hline Median duration of hospitalization (day) & $11(5-36)$ & $8(5-30)$ & $22(10-36)$ & $<0.01$ \\
\hline Mortality & $1(1.3)$ & 0 & $1(3.3)$ & \\
\hline
\end{tabular}

Values are presented as median (range), number (\%), or mean \pm standard deviation.

ESR, erythrocyte sedimentation rate; CRP, C-reactive protein; CMV, cytomegalovirus; IHC, immunohistochemistry; PCR, polymerase chain reaction; UCEIS, ulcerative colitis endoscopic severity index; FCP, fecal calprotectin; AllMS, All India Institute of Medical Sciences.

\section{Clinical and Laboratory Parameters during Hospitalization}

Median stool frequency on the day of presentation was 10 (620 ) which decreased to 7 (2-12) on day 3 of IV corticosteroids (Table 2). Patients needing rescue therapy and/or colectomy had a higher stool frequency on day of admission (11 [9-18] vs. 9 [6-20]; $P=0.11)$ and day 3 of IV corticosteroids $(7[4-14)$ vs. $5[2-15] ; P=0.06)$. Patients with steroid failure also had higher baseline UCEIS on sigmoidoscopy (6 [4-8] vs. 5 [3-7]; $P=0.04)$ and higher FCP level on day 3 of IV steroid $(1,383.8$ $\mu \mathrm{g} / \mathrm{g}[330-7,427]$ vs. $747 \mu \mathrm{g} / \mathrm{g}[44.2-4,062] ; P<0.01)$. Fourteen (47\%) patients in the steroid failure group were positive for both the criteria of AIIMS' index (AIIMS' index=2) compared to only 1 patient $(2 \%)$ in steroid responder group $(P<0.01)$. Forty-five patients (59\%) had positive CMV DNA PCR on mucosal biopsy. Patients with steroid failure had a significantly higher mucosal CMV DNA load as compared to steroid responders $(3,454$ copies/mg $[0-2,700,000]$ vs. 116 copies/mg $[0-27,220] ; P=0.004)$. CMV IHC on biopsy specimen was positive in 12 patients (16\%) (Table 2). Only 1 patient had an inclusion body detected on histopathological examination. Patients received IV steroids for a median 5 days (range, 5-10 days) with duration of hospital stay being 11 days (range, 5-36 days). Two patients developed toxic megacolon, both underwent colectomy. One patient who was operated on 9th day of hospital admission without any rescue medical therapy, died on postoperative day 3 from ventricular arrhythmia due to hypokalemia.

\section{CMV DNA Load as Predictor of Steroid-Response}

Positive IHC for CMV in biopsy or mere CMV PCR positivity were not significantly different between steroid responders 
Table 3. Multivariable Analysis for Prediction of Steroid Failure in Acute Severe Ulcerative Colitis

\begin{tabular}{|c|c|c|c|c|}
\hline \multirow{2}{*}{ Variable } & \multicolumn{2}{|c|}{ Univariable analysis } & \multicolumn{2}{|c|}{ Multivariableanalysis } \\
\hline & OR $(95 \% \mathrm{Cl})$ & $P$-value & OR $(95 \% \mathrm{Cl})$ & $P$-value \\
\hline AllMS' index $(\text { score }=2)^{a}$ & $39.4(4.8-323.9)$ & $<0.01$ & $39.8(4.4-364.4)$ & $<0.01$ \\
\hline CMV DNA quantitative $>2,000$ copies $/ \mathrm{mg}$ & $9.4(2.9-30.3)$ & $<0.01$ & $10.2(2.6-39.7)$ & $<0.01$ \\
\hline Day 3 stool frequency & $4.2(1.0-23.4)$ & 0.06 & $2.3(0.7-20.3)$ & 0.21 \\
\hline
\end{tabular}

${ }^{2}$ AllMS' index: baseline UCEIS > 6+day 3 FCP $>1,000 \mu \mathrm{g} / \mathrm{g}$.

OR, odds ratio; $\mathrm{Cl}$, confidence interval; AllMS, All India Institute of Medical Sciences; CMV, cytomegalovirus; UCEIS, ulcerative colitis endoscopic index of severity; FCP, fecal calprotectin.

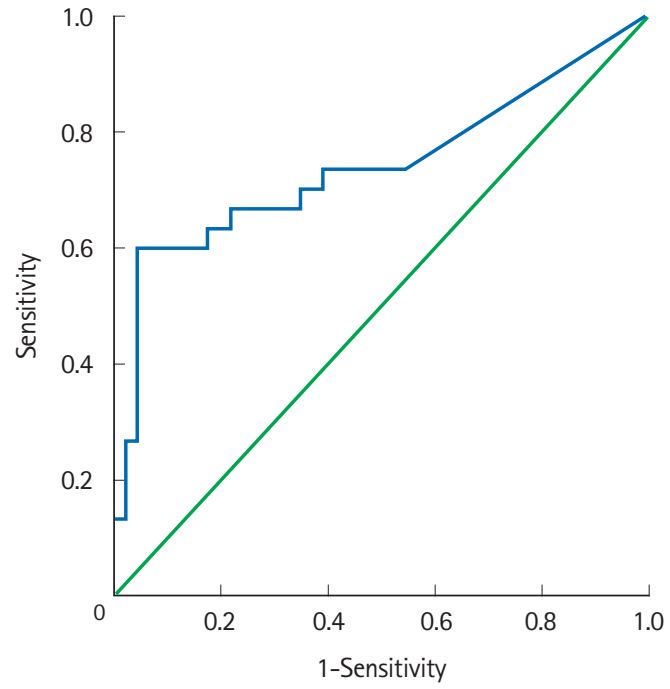

Fig. 2. Receiver operating curve of mucosal quantitative cytomegalovirus polymerase chain reaction for prediction of steroid failure in acute severe ulcerative colitis (ASUC) with an area under the curve of $74 \%$ (95\% confidence interval, 61-87). A cutoff of 2,000 copies/mg had a sensitivity of $67 \%$ and specificity of $70 \%$ for prediction of steroid failure in ASUC.

and failures ( $13 \%$ vs. $20 \%, P=0.41$ and $52 \%$ vs. $70 \%, P=0.15$; respectively). However, patients with steroid failure had a significantly higher mucosal CMV DNA load as compared to steroid responders (Table 2). The cutoff value for quantitative CMV DNA load to predict steroid-failure was derived from a receiver operating characteristic curve. Mucosal CMV DNA $>2,000$ copies/mg on admission could discriminate between steroid-failures and responders with a sensitivity of $53 \%$, specificity $90 \%$ and area under the curve of $74 \%$ (95\% confidence interval [CI], 61-87) (Fig. 2).

\section{Multivariable Analysis}

On univariate analysis baseline UCEIS, day 3 stool frequency, day 3 FCP, patients fulfilling AIIMS' index, and quantitative CMV DNA $>2,000$ copies/mg met the criteria for multivari-
Table 4. Quantitative CMV PCR and AlIMS Index for Prediction of Steroid Failure in Acute Severe Ulcerative Colitis

\begin{tabular}{lcccc}
\hline & $\begin{array}{c}\text { Sensiti- } \\
\text { vity (\%) }\end{array}$ & $\begin{array}{c}\text { Specifi- } \\
\text { city (\%) }\end{array}$ & $\begin{array}{c}\text { PPV } \\
\text { (\%) }\end{array}$ & $\begin{array}{c}\text { NPV } \\
\text { (\%) }\end{array}$ \\
\hline $\begin{array}{l}\text { AllMS' index positive } \\
\text { (score }=2)\end{array}$ & 47 & 98 & 93 & 74 \\
$\begin{array}{l}\text { Tissue CMV DNA > 2,000 } \\
\text { copies/mg }\end{array}$ & 53 & 89 & 76 & 74 \\
$\begin{array}{l}\text { AllMS index positive or tissue } \\
\text { CMV DNA > 2,000 copies/mg }\end{array}$ & 80 & 87 & 80 & 87 \\
\hline
\end{tabular}

aAlIMS' index: baseline UCEIS $>6+$ day 3 FCP $>1,000 \mu \mathrm{g} / \mathrm{g}$.

CMV, cytomegalovirus; PCR, polymerase chain reaction; AlIMS, All India Institute of Medical Sciences; PPV, positive predictive value; NPV, negative predictive value; UCEIS, ulcerative colitis endoscopic index of severity; FCP, fecal calprotectin.

able analysis between steroid-failures and responders. However due to collinearity between baseline UCEIS, day 3 FCP and AIIMS' index, only day 3 stool frequency, AIIMS' index and CMV DNA > 2,000 copies/mg were entered into multivariable model. On multivariable analysis, only CMV DNA quantitative $>2,000$ copies $/ \mathrm{mg}$ (odds ratio [OR], 10.2; 95\% CI, 2.6$39.7 ; P<0.01)$ and AIIMS' index (a score of 2) (OR, 39.8; 95\% CI, 4.4-364.4; $P<0.01)$ remained significantly associated with steroid-failure (Table 3 ).

Quantitative CMV PCR >2,000 copies/mg and AIIMS' index were also found to be the only significant predictors of colectomy at index admission (Supplementary Table 1).

\section{CMV PCR and AIIMS Index for Predicting Steroid Response}

AIIMS' index had very high specificity for predicting steroid failure in patients with ASUC but had a sensitivity of only $47 \%$ (Table 4). But using mucosal CMV DNA load along with AIIMS' index (mucosal CMV DNA load $>2,000$ copies/mg or AIIMS' index positive) markedly increased the sensitivity $(80 \%)$ to predict steroid failure (Table 4 ). That way we could 


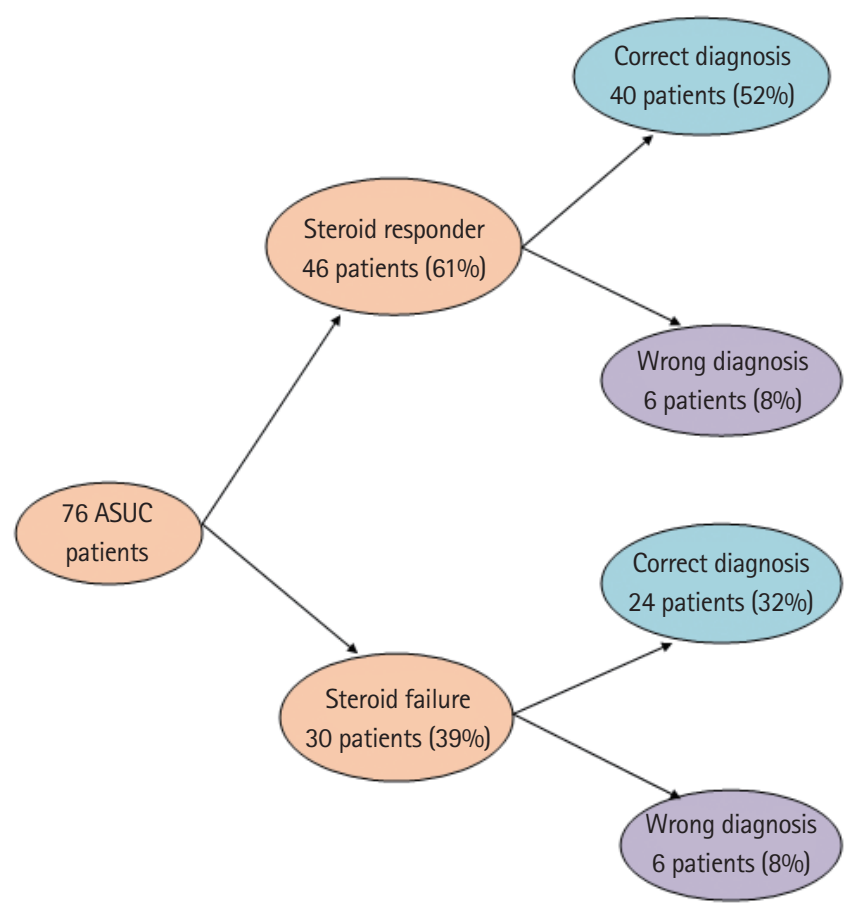

Fig. 3. Prediction of steroid response in acute severe ulcerative colitis (ASUC) patients using All India Institute of Medical Sciences index and high mucosal cytomegalovirus DNA load $(>2,000$ copies/mg).

correctly predict steroid response in 64 of $76(84 \%)$ patients of ASUC on 3rd day of IV steroid (Fig. 3). Of 46 steroid responders, 40 patients were negative for AIIMS' index, and had CMV PCR $<2,000$ copies/mg, and of 30 steroid failures, 24 were positive for either AIIMS' index or had CMV PCR $>2,000$ copies/mg (Fig. 3).

\section{Treatment for CMV}

Seven episodes of ASUC were treated with injection ganciclovir along with steroid in this cohort. The treatment decision was based on IHC positivity, patients' clinical history and judgment of treating physician. Median mucosal CMV DNA load in those 7 patients was 8,340 copies/mg (range, 1,270$2,700,000$ copies/mg). Four of them improved and did not require further rescue therapy. They were included in the steroid responder group. Three patients did not respond, 2 underwent surgery and 1 treated with infliximab.

\section{DISCUSSION}

There exists a therapeutic gap with IV steroids in ASUC which is rescued by surgery or advanced immunosuppression. ${ }^{1}$ Op- timum outcome on rescue therapy requires predicting nonresponse to steroids in a time bound manner, which has led to development of several predictive scores utilizing stool frequency, CRP, FCP and endoscopic severity. Fulminant episodes in the disease course of UC can also be precipitated by viral, bacterial or parasitic superinfections, and could also be responsible for nonresponse to IV steroids in addition to disease related factors. ${ }^{23}$ Present study explored this concept and showed that high mucosal CMV DNA load in these patients is a major predictor for nonresponse to IV steroid and need for colectomy. Thirty (39\%) patients in the present study had steroid failure, 12 (16\%) underwent colectomy and 20 (26\%) received rescue medical therapy. Two patients underwent colectomy after failure of rescue infliximab therapy. The diversity of choice of rescue therapy was mainly based on patients' preference or financial constraints.

Depending upon diagnostic tests, CMV positivity in the present cohort varied from $16 \%$ based on tissue IHC to $59 \%$ as detected in CMV PCR. Only 1 patient had presence of inclusion body in the biopsy. The prevalence of CMV infection in patients with steroid refractory UC varies across series, and has been reported to be similar to other patients, or significantly higher than steroid responsive group. ${ }^{13,14,24,25}$ The positivity rates vary depending upon the method of detection. Although it is not well established, most experts agree upon histology/IHC as the most specific tests for detection of colonic CMV infection. ${ }^{10}$ However these are limited by poor sensitivity and delay in diagnosis, which requires a test with better sensitivity and rapid turnaround time to evaluate the significance of CMV positivity on the outcomes in ASUC. In this regard, CMV mucosal quantitative PCR is an objective quantitative method for detection of CMV in the tissue with results being available within 24 hours. ${ }^{15,26,27}$ In the present study, quantitative CMV PCR could detect CMV in 59.2\% of patients with ASUC, which was significantly higher than that by IHC (15.7\% only). Similar to the present study, in a study by Yoshino et al., ${ }^{13}$ among 30 patients with steroid refractory acute severe colitis, quantitative PCR for CMV DNA in mucosal biopsy was positive in 17 patients, of which only 4 were positive for IHC, highlighting the limited sensitivity of IHC as compared to quantitative CMV PCR. Of those 17 CMV-DNA-positive patients, 10 patients were successfully treated with ganciclovir and 12 of the 13 CMV-DNA-negative patients (92.3\%) achieved remission after intensifying their immunosuppressive therapies.

Previous studies have reported conflicting results regarding the value of mucosal CMV PCR as a predictor of outcomes in 
patients with ASUC. In a recent pediatric study of 56 patients with ASUC, 27\% were CMV positive of which 93\% were steroid refractory and $20 \%$ required colectomy during hospitalization, and additional one-third required over next 1 year, highlighting the influence of CMV on short- and long-term outcomes in ASUC. ${ }^{28}$ Similarly, in 2 other studies of 95 (33 CMV IHC positive) and 149 patients (50 CMV positive on IHC/histopathology examination), the colectomy rates and need for rescue therapy was significantly higher in CMV positive patients. ${ }^{9,11}$ However, in a case-control study of hospitalized UC patients, though the hospital stay was longer in those with concomitant CMV infection $(\mathrm{n}=145)$ than non-CMV group $(n=14,690)$, the colectomy rates and mortality were similar. ${ }^{10}$ Prevalence of CMV has also been correlated with severity of ASUC as evidenced significantly higher prevalence of CMV in patients with toxic megacolon than those without (46\% vs. $9 \%) .{ }^{29}$ In the present study, IHC positivity and mere positivity for mucosal CMV DNA was not predictive of steroid nonresponse. However, high CMV DNA load of $>2,000$ copies/mg was able to predict steroid failure with a reasonable diagnostic accuracy, having a sensitivity of $53 \%$ and specificity of $90 \%$. Like the present study, Roblin et al. ${ }^{15}$ in a study of 42 patients also showed that CMV DNA $>250$ copies/mg was predictive of steroid failure. The differences in the cutoff values between ours and this study could be due to differences in definitions of ASUC, response to steroid and patient population.

We further analyzed the significance of CMV quantification in relation to disease severity as quantified by the AIIMS' index (combination of baseline UCEIS and day 3 FCP). Interestingly, on multivariate analysis, high CMV mucosal DNA load ( $>2,000$ copies/gm) was an additional predictor of steroid failure (OR, 10.2; 95\% CI, 2.6-39.7) and colectomy (OR, 17.2; 95\% CI, 2.6-115.2) in addition to AIIMS' index (OR, 39.8; 95\% CI, 4.4-364.4 for steroid failure and OR, 18.2; 95\% CI, 2.9114.4 for colectomy). AIIMS' index was a stronger predictor than CMV DNA load, indicating that disease severity is the most important predictor for steroid nonresponse, but significance of CMV positivity in this setting indicates the additional value of CMV testing at baseline in a patient with ASUC. Further, on combining AIIMS' index and CMV load, we were able to correctly predict outcomes (steroid response or failure) in $84 \%$ patients, and if a patient had either AIIMS' index positive or CMV load $>2,000$ copies $/ \mathrm{mg}$, this resulted in a sensitivity of $80 \%$ and specificity of $87 \%$ in predicting steroid failure.

Although done prospectively with a reasonable sample size, the study has certain limitations. We have demonstrated CMV DNA as an independent predictor of short-term outcomes in ASUC, but we could not dissect out its role-a marker of severe disease or a pathogenic agent increasing severity. Albeit some studies showed the usefulness of CMV viremia or antigenemia in this setting, we did not test it in our patients. ${ }^{9,30} \mathrm{We}$ could treat only 7 episodes with ganciclovir as the decision to treat was based on IHC positivity, which precluded us from making any conclusion. We did not include results of longterm follow-up, as we intended to highlight the effect of CMV on steroid response and short-term outcomes of ASUC. So, a large prospective study with treatment decisions based upon CMV DNA results is needed to clarify the unanswered questions of the present study. Despite these limitations this study evaluated the role of quantitative CMV PCR in relation to other markers of disease severity as a predictor of steroid failure or colectomy in a reasonably large cohort of patients with ASUC.

To conclude high mucosal CMV DNA load ( $>2,000$ copies/ $\mathrm{mg}$ ) independently predicts failure of IV corticosteroids and short-term risk of colectomy in patients with ASUC. It has an additional value to the established markers of disease severity in ASUC.

\section{ADDITIONAL INFORMATION}

\section{Funding Source}

This work was supported in part by the National Institute for Health Research (NIHR) Oxford Biomedical Research Centre (BRC) and Scheme for Promotion of Academic and Research Collaborations (SPARC).

\section{Conflict of Interest}

Travis SP is an editorial board member of the journal but was not involved in the peer reviewer selection, evaluation, or decision process of this article. No other potential conflicts of interest relevant to this article were reported.

\section{Author Contribution}

Conceptualization: Jain S, Namdeo D, Sahu P, Kedia S, Ahuja V. Data curation: Jain S, Namdeo D, Sahu P. Formal analysis: Jain S, Sahu P, Ahuja V. Funding acquisition: Ahuja V. Investigation: Jain S, Namdeo D, Sahu P, Kedia S, Das P, Sharma R, Dar L. Methodology: Jain S, Namdeo D, Sahu P, Kedia S, Ahuja V. Project administration: Kedia S, Sahni P, Makharia G, Dar L. Supervision: Kedia S, Sahni P, Das P, Sharma R, Gupta V, Makharia G, 
Dar L, Travis SP, Ahuja V. Validation: Jain S, Namdeo D, Sahu P, Kedia S, Sahni P, Das P, Gupta V, Travis SP, Ahuja V. Writing original draft: Jain S, Namdeo D, Sahu P. Writing - review \& editing: Jain S, Namdeo D, Sahu P, Kedia S, Sahni P, Das P, Travis SP, Ahuja V. Approval of final manuscript: all authors.

\section{Others}

We are particularly grateful to our patients, colleagues, nursing, pharmacy, clerical staff and allied professionals who collectively support our IBD services and enable studies such as this to be performed.

\section{ORCID}

Jain S

Namdeo D

Sahu P

Kedia S

Sahni P

Das P

Sharma R

Gupta V

Makharia G

Dar L

Travis SP

Ahuja V

https://orcid.org/0000-0002-2947-7836

https://orcid.org/0000-0001-5276-2398

https://orcid.org/0000-0002-9847-0136

https://orcid.org/0000-0002-5758-0144

https://orcid.org/0000-0002-6910-062X

https://orcid.org/0000-0002-2420-8573

https://orcid.org/0000-0001-5181-263X

https://orcid.org/0000-0002-9620-1696

https://orcid.org/0000-0002-2474-2194

https://orcid.org/0000-0002-9228-1799

https://orcid.org/0000-0002-2690-4361

https://orcid.org/0000-0002-1577-0118

\section{Supplementary Material}

Supplementary materials are available at the Intestinal Research website (https://www.irjournal.org).

\section{REFERENCES}

1. Dinesen LC, Walsh AJ, Protic MN, et al. The pattern and outcome of acute severe colitis. J Crohns Colitis 2010;4:431-437.

2. Cesarini M, Collins GS, Rönnblom A, et al. Predicting the individual risk of acute severe colitis at diagnosis. J Crohns Colitis 2017;11:335-341

3. Turner D, Walsh CM, Steinhart AH, Griffiths AM. Response to corticosteroids in severe ulcerative colitis: a systematic review of the literature and a meta-regression. Clin Gastroenterol Hepatol 2007;5:103-110.

4. Travis SP, Farrant JM, Ricketts C, et al. Predicting outcome in severe ulcerative colitis. Gut 1996;38:905-910.

5. Lindgren SC, Flood LM, Kilander AF, Löfberg R, Persson TB, Sjödahl RI. Early predictors of glucocorticosteroid treatment failure in severe and moderately severe attacks of ulcerative colitis. Eur J Gastroenterol Hepatol 1998;10:831-835.

6. Jain S, Kedia S, Bopanna S, et al. Faecal calprotectin and UCEIS predict short-term outcomes in acute severe colitis: prospective cohort study. J Crohns Colitis 2017;11:1309-1316.

7. Le Baut G, Kirchgesner J, Amiot A, et al. A scoring system to determine patients' risk of colectomy within 1 year after hospital admission for acute severe ulcerative colitis. Clin Gastroenterol Hepatol 2021;19:1602-1610.

8. Papadakis KA, Tung JK, Binder SW, et al. Outcome of cytomegalovirus infections in patients with inflammatory bowel disease. Am J Gastroenterol 2001;96:2137-2142.

9. Lee HS, Park SH, Kim SH, et al. Risk factors and clinical outcomes associated with cytomegalovirus colitis in patients with acute severe ulcerative colitis. Inflamm Bowel Dis 2016;22:912918.

10. Grossberg LB, Ezaz G, Grunwald D, Cohen J, Falchuk KR, Feuerstein JD. A national survey of the prevalence and impact of cytomegalovirus infection among hospitalized patients with ulcerative colitis. J Clin Gastroenterol 2018;52:241-245.

11. Zagórowicz E, Bugajski M, Wieszczy P, Pietrzak A, Magdziak A, Mróz A. Cytomegalovirus infection in ulcerative colitis is related to severe inflammation and a high count of cytomegalovirus-positive cells in biopsy is a risk factor for colectomy. J Crohns Colitis 2016;10:1205-1211.

12. Levin A, Yaari S, Stoff R, Caplan O, Wolf DG, Israeli E. Diagnosis of cytomegalovirus infection during exacerbation of ulcerative colitis. Digestion 2017;96:142-148.

13. Yoshino T, Nakase H, Ueno S, et al. Usefulness of quantitative real-time PCR assay for early detection of cytomegalovirus infection in patients with ulcerative colitis refractory to immunosuppressive therapies. Inflamm Bowel Dis 2007;13:15161521.

14. Okahara K, Nagata N, Shimada T, et al. Colonic cytomegalovirus detection by mucosal PCR and antiviral therapy in ulcerative colitis. PLoS One 2017;12:e0183951.

15. Roblin X, Pillet S, Oussalah A, et al. Cytomegalovirus load in inflamed intestinal tissue is predictive of resistance to immunosuppressive therapy in ulcerative colitis. Am J Gastroenterol 2011;106:2001-2008.

16. Dignass A, Eliakim R, Magro F, et al. Second European evidence-based consensus on the diagnosis and management of ulcerative colitis part 1: definitions and diagnosis. J Crohns Colitis 2012;6:965-990.

17. Truelove SC, Witts LJ. Cortisone in ulcerative colitis; preliminary report on a therapeutic trial. Br Med J 1954;2:375-378.

18. Magro F, Gionchetti P, Eliakim R, et al. Third European evi- 
dence-based consensus on diagnosis and management of ulcerative colitis. part 1: definitions, diagnosis, extra-intestinal manifestations, pregnancy, cancer surveillance, surgery, and ileo-anal pouch disorders. J Crohns Colitis 2017;11:649-670.

19. Silverberg MS, Satsangi J, Ahmad T, et al. Toward an integrated clinical, molecular and serological classification of inflammatory bowel disease: report of a Working Party of the 2005 Montreal World Congress of Gastroenterology. Can J Gastroenterol 2005;19 Suppl A:5A-36A.

20. Travis SP, Schnell D, Krzeski P, et al. Reliability and initial validation of the ulcerative colitis endoscopic index of severity. Gastroenterology 2013;145:987-995.

21. Bradford RD, Cloud G, Lakeman AD, et al. Detection of cytomegalovirus (CMV) DNA by polymerase chain reaction is associated with hearing loss in newborns with symptomatic congenital CMV infection involving the central nervous system. J Infect Dis 2005;191:227-233.

22. Griscelli F, Barrois M, Chauvin S, Lastere S, Bellet D, Bourhis JH. Quantification of human cytomegalovirus DNA in bone marrow transplant recipients by real-time PCR. J Clin Microbiol 2001;39:4362-4369.

23. Banerjee D, Deb R, Dar L, et al. High frequency of parasitic and viral stool pathogens in patients with active ulcerative colitis: report from a tropical country. Scand J Gastroenterol 2009;44:325-331.

24. Nakase H, Yoshino T, Ueno S, et al. Importance of early detec- tion of cytomegalovirus infection in refractory inflammatory bowel disease. Inflamm Bowel Dis 2007;13:364.

25. Clos-Parals A, Rodríguez-Martínez P, Cañete F, et al. Prognostic value of the burden of cytomegalovirus colonic reactivation evaluated by immunohistochemical staining in patients with active ulcerative colitis. J Crohns Colitis 2019;13:385-388.

26. Landry ML, Ferguson D. Comparison of quantitative cytomegalovirus antigenemia assay with culture methods and correlation with clinical disease. J Clin Microbiol 1993;31: 2851-2856.

27. Kou T, Nakase H, Tamaki H, Kudo T, Nishio A, Chiba T. Cytomegalovirus infection in patients with ulcerative colitis diagnosed by quantitative real-time PCR analysis. Dig Dis Sci 2006;51:1052-1055.

28. Cohen S, Martinez-Vinson C, Aloi M, et al. Cytomegalovirus infection in pediatric severe ulcerative colitis-a multicenter study from the pediatric inflammatory bowel disease Porto group of the European society of pediatric gastroenterology, hepatology and nutrition. Pediatr Infect Dis J 2018;37:197201.

29. Criscuoli V, Rizzuto MR, Gallo E, Orlando A, Cottone M. Toxic megacolon and human cytomegalovirus in a series of severe ulcerative colitis patients. J Clin Virol 2015;66:103-106.

30. Chun J, Lee C, Kwon JE, et al. Usefulness of the cytomegalovirus antigenemia assay in patients with ulcerative colitis. Intest Res 2015;13:50-59. 
See "High mucosal cytomegalovirus DNA helps predict adverse short-term outcome in acute severe ulcerative colitis" on page $438-447$.

Supplementary Table 1. Multivariable Analysis for Prediction of Colectomy during Index Admission in Acute Severe Ulcerative Colitis

\begin{tabular}{lcc}
\hline Variable & OR $(95 \% \mathrm{Cl})$ & $P$-value \\
\hline $\begin{array}{l}\text { Quantitative CMV DNA } \\
>2,000 \text { copies/mg }\end{array}$ & $17.2(2.6-115.2)$ & $<0.01$ \\
AllMS index & $18.2(2.9-114.4)$ & $<0.01$ \\
\hline
\end{tabular}

OR, odds ratio; $\mathrm{Cl}$, confidence interval; CMV, cytomegalovirus; AlIMS, All India Institute of Medical Sciences. 